\title{
POTENTIAL DEVELOPMENTS OF WASTE MANAGEMENT IN ITALY
}

\author{
Alessandra Ruffini \\ June 2021
}

\section{INTRODUCTION}

Waste management is an issue that is gaining relevance among professionals and legislators. This increase is due to the huge amount of waste that every year is produced because of consumistic generations and shorter product life cycles.

Taking into consideration the global heat-warming process and that the overshoot day comes earlier every year, Countries are called to implement eco-friendly solutions. Since there is a huge variety of topics that can be discussed, this article focuses on waste management processes that have been implemented in Italy in a circular economy perspective. Since circular economy still has unexploited potentials, is interesting to highlight possible courses of actions that can be taken in the near future to improve the current state. In this review we will keep a particular attention to the case of Italy.

\section{TYPES OF WASTE AND THEIR RECOVERY PROCESSES}

Waste can be defined as any element that is discarded by the owner of the product. According to its origin and hazardousness, waste can be divided into three major categories:

The first one is hazardous waste, which is anything that represents the characteristics described in Annex III of Waste Framework Directive 2008/98/EC [2]. It's originated by hazardous materials contained into products and, because of the risks they can cause, they must be indicated on products' labels.

The second category regards e-waste, considered as any electronic equipment not useful anymore and whose disposal is difficult. E-products have increased their relevance in everyday lives and enterprises shorten their product life cycle duration to create updated versions that customers are willing to buy, throwing away the old e-product which becomes e-waste. Even if many of them can be sold to someone else, given to a charity, refurbished to give them a new life or recycled, today, e-waste has a high growth rate because electronics have a very short useful life. According to Haque (2019, [7]), "in 2014 only 10 to 40 percent of disposal is done properly" and, according to EPA, the current e-waste recycling rate is just at 12.5\% (see Haque, 2019 [7]). Finally, the third class is municipal solid waste (MSW). As described by the European Environment Agency, it "is mainly produced by households, though similar wastes from sources such as commerce, offices and public institutions are included. The amount of municipal waste generated consists of waste collected by or on behalf of municipal authorities and disposed of through the waste management system" (see European Environment Agency, 2013 [4]). This is the major kind of waste, which has to be taken into consideration primarily. It is composed by four macro-classes: plastics, bio-waste, metals and glass.

Plastic

It is the major component. Its mass production started in 1950s with 2 million tonnes per year, it increased exponentially and in 2015 the production reached ... tons, a value equivalent to the mass of $2 / 3$ of the world population (see Ritchie and Roser, 2018 [17]), with a short downturn in 2009-2010 caused by the 2008 global financial crisis.

This huge amount of plastic must be managed at the end of its life cycle. Until 1980, 100\% of plastics were discarded and only recently recycling and incineration have been used. The projections of 2050 waste disposal, as indicated by Geyer et al. (2017, [6]) highlights how the percentages of incineration and recycling are likely to increase at 50 and $44 \%$ respectively while the discarded amount may fall to $6 \%$.

Bio waste

Another type of MSW is bio-waste, which is defined as "biodegradable garden and park waste, food and kitchen waste from households, restaurants, caterers and retail premises and comparable waste from food processing plants" from the European Commission (see Directive 2008/98/EC, [2]). Bio-waste can be assumed to account for the $40 \%$ of the total municipal waste ${ }^{1}$.

\footnotetext{
${ }^{1}$ Data available in EUROSTAT municipal waste database at http://ec.europa.eu/eurostat/data/database
} 
Bio-waste collection did not improve over the last years with respect to the final disposal and in order to mitigate this problem, different solutions are taking place: starting from the UN 17 SDGs, which promote responsible consumption and production in sustainable cities and communities, to the Circular Economy package implemented by the European Union.

In circular economy, bio-waste obtains a new value because it's a resource for organic soil improvers, fertilisers and bio-based products. In fact, the carbon and nutrients can be extracted and transformed into a wide range of bio-based products that replace fossil-based products.

\section{Metals}

Metals are valuable materials that can be recycled repeatedly without altering their properties. They are widespread components of everyday products.

They are recycled for four main reasons: first, they don't lose their properties in being disposed; second, they generate financial gains by reselling scrap metal; third, cost-savings from the lower use of energy in their disposal process; fourth, the environmental necessity of preserving natural resources.

Despite the properties and the huge amount used every day, only $30 \%$ is recycled every year worldwide (see LeBlanc, 2018 [14]). Considering its characteristics and the benefits, this percentage is not acceptable, and it must be improved through the redesign of metal products to reduce their complexity, public awareness and community recycling programs.

\section{Glass}

Finally, among the MSW we recall glass. It is another material that can be recycled over and over without losing its properties. First, it protects the environment because $\mathrm{CO}_{2}$ emissions generated from its recycle process can decrease up to $45 \%^{2}$ and eventual discarded components can be recycled themselves. Second, melting processes are cost-saving.

Third, glass recycling process is fast: for example, if we take a recycling bin and we recycle it, the glass container that we obtain from the recycling process arrives on a store shelf in something like 30 days (see LeBlanc, 2019 [15]).

\section{Dismantling processes}

Now that we have introduced the types of waste, we must proceed with their recovery processes. The dismantling of MSW can be done in different ways. The most common processes adopted for glass and plastics are:

1. Landfilling

2. Incineration

3. Recycling

Each of them is characterized by different levels of "greenity" and environmental sustainability.

Over the last few decades, landfills replaced dumping. Landfills are disposal sites, regulated from siting to filling and closing: modern landfills compact waste to increase density and stability and cover it up to prevent pests. They have safeguards to control the facility and pipes to vent, incinerate or store the gases generated by organic waste decomposition that can be used to generate electricity.

This is the least preferable option and should be limited because it still has negative environmental impacts. The second alternative is incineration. At the beninning, waste was burnt but now waste-to-energy facilities have been developed to generate heat, steam and electricity.

This alternative has some pros: the bottom ash is non-injurious, emissions are controlled, fine particles can be removed and the waste-to-energy plants can substitute power generation plants of other sort. However, incineration has also significant cons: it still produces emissions that are largely composed of carbon dioxide, which is the primary cause of global climate change, and it contains highly toxic emissions, that are dangerous for human and ecosystem health.

Its net impact depends on the efficiency of the energy recovery process and of the facility.

The first recycling practices date back to the $18^{\text {th }}$ century but only in late 1960 s with growing environmental movements they were taken into consideration again.

Recycling is "any recovery operation by which waste materials are reprocessed into products, materials or substances whether for the original or other purposes. It includes the reprocessing of organic material but does not include energy recovery and the reprocessing into materials that are to be used as fuels or for backfilling operations" (see Directive 2008/98/EC, [2]).

\footnotetext{
${ }^{2}$ See Ferver website at http://www.ferver.eu/en/why-recycle-glass
} 
Recycling, together with more effective material design, can reduce both the need of new raw materials and the final volume of waste. It therefore contributes to keep cleaner land, air, water and as an ultimate benefit, overall better health. Notwithstanding, recycling rates have started a steady increase only in the $21^{\text {st }}$ century to face the traditional disposal fees increases.

Among these three alternatives, recycling is clearly the preferrable one, given its ecological and economic advantages.

\section{CRITICAL ASPECTS}

Before considering the Italian case, it is relevant to observe some major aspects of the waste management in the EU. The situation changes significantly across the different European states. The following figure represents the municipal waste per capita produced by 32 European Countries in the period 2001 - 2010: Italy had a slightly increase in this time range. There is an inverse relationship between the size of each country and the amount of municipal waste per capita produced. The smallest European Countries, like Cyprus, Switzerland and Luxembourg, are the first three on the left while Slovakia, Poland and Romania are at the bottom.. Italy stands in the low-middle section. This relationship must consider socio-economical factors, such as the population density of each country. For example, Latvia is a small country with $30^{3}$ people per $\mathrm{km}^{2}$ and it registers a small amount of waste (in fact, it's on the right), while Luxembourg, which is even smaller than Latvia, has a population density of $242^{4}$ people $/ \mathrm{km}^{2}$ and it's on the left with a huge amount of municipal waste per capita.

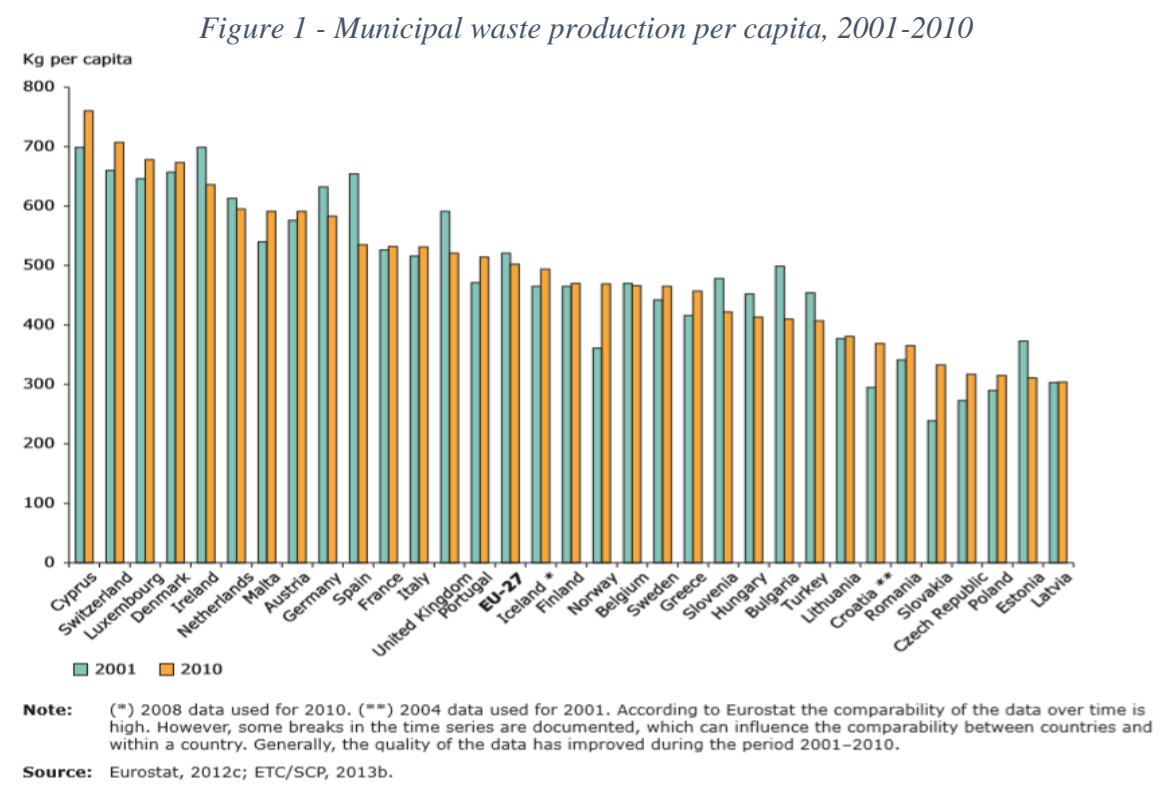

We can look at the composition of waste in the following figure, which provides an overview of waste produced by economic activities and households in 2016. The quantity of each country is related to its population and economic size: for example, Bulgaria and Romania have a relative greater quantity than Italy. Italy has a huge percentage in manufacturing (17\%) and construction and demolition (33\%) fields, with an average of $29 \%$ covered by other economics activities. Also households cover the $18 \%$. In a circular economy perspective, there is a huge field of implementation, because it allows to transform the waste coming from manufacturing, construction and demolition into valuable green resources. From these activities old windows, doors, walls components, cables, etc... can be transformed into new products: as explained before glass from windows and metals from cables can be recycled many times without losing their properties, old doors can be restored or transformed into new products, libraries for example, and so on.

\section{ITALIAN WASTE MANAGEMENT SYSTEM}

The Circular Economy Network and ENEA, (The National Agency for New Technologies, Energy and Environmental Sustainable Development) have published a "Circular Economy in Italy Report" ([18]).They

\footnotetext{
${ }^{3}$ Latvia population density data source: https://www.worldometers.info/demographics/latvia-demographics/

${ }^{4}$ Luxembourg population density data source: https://www.worldometers.info/world-population/luxembourgpopulation/
} 
compared five of the most important European economies (France, Germany, Spain, The United Kingdom and Italy) on five dimensions:

- Production

- Consumption

- Waste management

- Secondary raw materials market

- Investments and labour

Figure 2 - Waste production by economic activities and households, 2016

\begin{tabular}{|c|c|c|c|c|c|c|}
\hline & $\begin{array}{l}\text { Mining and } \\
\text { quarrying }\end{array}$ & Manufacturing & Energy & $\begin{array}{l}\text { Construction and } \\
\text { demolition }\end{array}$ & $\begin{array}{c}\text { Other economic } \\
\text { activities }\end{array}$ & Households \\
\hline EU-28 & 25 & 10 & 3 & 36 & 16 & 8 \\
\hline Belgium & 0 & 23 & 1 & 31 & 36 & 8 \\
\hline Bulgaria & 82 & 3 & 8 & 2 & 3 & 2 \\
\hline Denmark & 0 & 5 & 4 & 58 & 16 & 17 \\
\hline Germany & 2 & 14 & 3 & 55 & 17 & 9 \\
\hline Estonia & 26 & 37 & 25 & 5 & 6 & 2 \\
\hline Ireland (') & 18 & 23 & 2 & 12 & 35 & 10 \\
\hline France & 1 & 7 & 0 & 69 & 14 & 9 \\
\hline Croatia & 12 & 8 & 2 & 24 & 31 & 22 \\
\hline Italy & 0 & 17 & 2 & 33 & 29 & 18 \\
\hline Cyprus (') & 5 & 33 & 0 & 36 & 10 & 16 \\
\hline Latvia & 0 & 19 & 11 & 4 & 30 & 34 \\
\hline Lithuania & 1 & 41 & 2 & 8 & 32 & 17 \\
\hline Luxembourg & 0 & 7 & 0 & 75 & 11 & 6 \\
\hline Hungary & 1 & 17 & 16 & 23 & 25 & 18 \\
\hline Romania & 87 & 4 & 4 & 0 & 3 & 2 \\
\hline Slovenia & 0 & 25 & 14 & 10 & 39 & 12 \\
\hline Slovakia & 3 & 32 & 9 & 9 & 29 & 18 \\
\hline Finland & 76 & 8 & 1 & 11 & 3 & 1 \\
\hline Sweden & 77 & 4 & 1 & 7 & 7 & 3 \\
\hline United Kingdom & 6 & 4 & 0 & 49 & 30 & 10 \\
\hline Liechtenstein & 3 & 2 & 0 & 88 & 1 & 5 \\
\hline Norway & 3 & 14 & 2 & 27 & 32 & 22 \\
\hline Montenegro & 19 & 2 & 18 & 37 & 10 & 13 \\
\hline $\begin{array}{l}\text { Former Yugoslav Republic } \\
\text { of Macedonia }\end{array}$ & 49 & 51 & 0 & 0 & 0 & 0 \\
\hline Serbia & 79 & 3 & 12 & 1 & 2 & 3 \\
\hline Turkey & 11 & & 26 & : & 8 & 37 \\
\hline Kosovo* $^{*}$ & 14 & 20 & 40 & 6 & 10 & 11 \\
\hline
\end{tabular}

The analysis on production shows that Italy has maintained a stable position in 2018 with respect to the previous year. In particular, the Italian resources productivity is 3 euro of PIL for each kilogram consumed, showing a higher value than the European average, which is 2,24 euro. Anyway, Italy has not reached 2014 levels where the productivity was at $3,24 € / \mathrm{kg}$, which means that Italy can do better and in the last years the current value has kept constant. This shows that there is something that has stopped an increasing trend.

The same results occur for the energy productivity which is higher $(10,2 € / \mathrm{PIL})$ than the European mean $(8,5$ $€ / \mathrm{PIL})$, assessing Italy as the second European country and for the share of renewable energy which is in line with the European level ([18]). Furthermore, the comparison between the total waste production and the internal consumption of materials reaches the $22,7 \%$, with respect to the European level of 12,8\%. This higher level can be explained by the increase in the indicator DMC (Domestic Material Consumption) the indicator of 56\%, between 2004 and 2014, marking Italy with the worst level among the first five major economies ([18]). Despite this negative level, other variables help Italy to compensate the previous weakness, so that overall Italy has the best performance in production of waste in relation to the five other countries.

Talking about energy consumption, Italy is the $4^{\text {th }}$ European major consumer country and, The sharing mobility of Italy increased of 17\% between 2015 and 2017, fixing the Italian ranking to the $3^{\text {rd }}$ position among the five major EU economies 
With respect to recycling indicators of waste management, Italy is the $1^{\text {st }}$, together with Germany. In 2016 the Italian urban waste recycling percentage was at $45,1 \%$, while the total recycling percentage was $67 \%$, which is much higher than the European average. This measure, together with the landfilling decrease at 25\%, brings Italy up in the rank at the first place.

With respect to Secondary raw materials market Italy places to the third place. The circular usage of material rate is at $17,1 \%$ in 2016 , showing a decrease from the 2014 when it reached $18,5 \%$; the import-export of recycled material balance is negative and Italy imports 700.000 tons more than the quantity it exports.

Finally, considering investments and labour Italy covers the $2^{\text {nd }}$ place, despite the low number of patents (only 15 in 2015). The low eco-innovative input (three times lower than Germany) highlights the low level of public financing and private investments, even if the eco-innovation index places Italy over the European mean at the third position between the major economies. Furthermore, Italy has invested efficiently scarce resources to finance technological progress and cover the gap with other economies.

Decree Ronchi and Legislative Decree 152/2006

The Italian waste management regulation was born with the Decree Ronchi and obtained further development with the Legislative Decree 152/2006.

The Decree Ronchi (22/1997, [3]) was issued on February, $5^{\text {th }} 1997$ to recognize European Directives on waste (91/156/CE), hazardous waste (91/689/CEE), on packaging and its related waste (94/62/CE) and to discipline their application on the Italian territory.

The Law 22/1997 states that waste management is a public interest activity and it's disciplined to ensure efficient control and high environmental protection. In fact, Ronchi's law aims to the cooperation and empowerment of all the individuals involved in the production, distribution, use and consume of creating waste goods.

In 2006, the Legislative Decree 152/2006 [16] replaces Ronchi's Decree to upload the national legislation with the European legislation that was moving further.

The Legislative Decree 152/2006 introduces the Environmental Code, which presents the environmental impact evaluation, the soil defence, the protection of air and water, the remediation of polluted sites and the compensation for the environmental damage. Moreover, it confirms the applications dictated by the Decree Ronchi and changes the waste approach from disposal to recycling and management.

In particular, Article 179 sees the disposal as a residual activity and it's at the end of the waste hierarchy, preceded by prevention, preparing for re-use, recycling, other recovery.

The first one is prevention which aims at reducing the amount of waste produced: competent authorities have to promote the adoption of the best available technologies and have to develop a measurement system that computes the environmental impact of the product.

The second one is preparing for re-use through logistics measures like reuse networks and sites, educational activities, and criteria that favour agreements related to secondary raw materials.

The third one is recycling and the main goal was the implementation of the separate collection for paper, metal, plastic, glass and steel before 2015 .

The last one, handling is the residual choice if there is technical and economical impossibility to carry out the previous ones.

Three public institutions are competent in the Italian waste management system: CONAI (National Packaging Consortium), ISPRA (Italian Institute for Environmental Protection and Research) and AssoARPA (Association of Regional Agencies for Environmental Protection).

Furthermore, the Legislative Decree 152/2006 describes the competences of each authority following the principle of subsidiarity where the competence is on the agent who is the nearest to the issue. The Government has to coordinate the activities and rationalize the collection Regions have to establish waste management programs and regulate them, to promote the integrated waste management and authorize the activity.

Next, Municipalities must handle municipal waste and their management to guarantee a distinctive recycling process for each kind of waste.

CONAI

The National Packaging Consortium (CONAI) is a private non-profit consortium composed by 900.000 companies. It works with Municipalities and constitutes a guarantee to citizens that any material obtained from 
separate waste collections is fully used in proper recovery and recycling processes.

Its goals are the achievement of the overall targets of recycling and recovery packaging across the whole Italy, and the implementation of the targeted management policies by defining the transition from a landfilling based management system to an integrated one where prevention, recovery and recycling are the main adopted solutions.

To work in a more efficient manner, CONAI is organized into six Consortia. Each Consortia is related to one packaging material: steel (Ricrea), aluminium (Cial), paper (Comieco), wood (Rilegno), plastic (Corepla) and glass (Coreve).

Ricrea is the consortium that works on steel packaging collected by Italian municipalities through separate collection programs. According to the international ISO14001:2004, Ricrea has an Environmental Management System that aims at the betterment of environmental performances. In 2015 Ricrea recycled 348.000 tons of steel which accounts to $73.4 \%$ of the materials in the market ${ }^{5}$, while in 2017 it recycled 361.403 tons of steel $(75,3 \%)^{6}$ demonstrating an improvement with respect to two years before.

Then, Cial is the non-profit consortium related to aluminium. Its mission is to find a balance between the reduction of aluminium packages, their recovery, the satisfaction of demand and the environmental protection by recycling of post-consumption packaging that is collected by Italian municipalities. Its activity has two founding principles: the extended producer responsibility and "who pollutes, pays". With an increase in the quantities managed and strict collaboration with other institutions, it has been able to accomplish European objectives and to make Italy an example for the other Member States. In 2018 it recovered $70 \%{ }^{7}$ of the aluminium packaging present on the Italian market.

Next, Comieco is the non-profit consortium related to paper, cardboard and cellulose-based waste. From 1998 to 2015 , with the development of recycling, the percentage of recycled paper grew from $37 \%$ to $80 \%{ }^{8}$ and of this $80 \%, 88 \%{ }^{9}$ was recovered. These percentages must be integrated in the current industrial system which uses paper waste in industrial processes at a rate of 55\% and consumes 4.9 million of tons, which can be estimated at around 81 kilograms per inhabitant. That $80 \%$ and $88 \%$ demonstrate the huge effort that Comieco and the other economic agents are doing in protecting the environment: furthermore, thanks to the activity of Comieco and the entire system, Italy has moved from being an importer of millions of tons of paper waste to being a net exporter of used paper and cardboard.

The next one is Rilegno which recovers wooden packaging waste. It's a non-profit consortium which guarantees the separate collection and recycling of wood, and the achievement international objectives like the SDGs number 12 which stands for sustainable production and consumption models.

In 2018, it recycled more than 1.900 .000 tons of the 3.000.000 tons of wood packaging consumed, registering an increase of $7.74 \%$ from the previous year, and $65 \%$ of the managed wood was semi-processed for the furniture industry ${ }^{10}$. Furthermore, it served 42.115 .759 people which are the $69.51 \%$ of the national population, that live in 4.541 municipalities, from which it collected 642.469 tons of wood waste (65\% from the northern regions, $22 \%$ from the centre and $13 \%$ from the southern ones $)^{11}$.

Then, Corepla works on plastics but it doesn't organize or manage the separate collection of plastic packaging. It ensures the withdrawal of material, it gives to municipalities money to cover the major costs of the separate collection service.

Besides, Corepla works to develop advanced technological solutions that allow the conversion of nonrecyclable packaging into energy and heat. At the moment, there are two flows of waste that are recycled into energy: the first one is the amount which can't be used into the mechanical recycling process (plastic is cut into scales and granules to become secondary raw material and to enter a new production process) and its heterogeneity doesn't allow the reallocation on the market, so Corepla sends it to the production of alternative fuel; the second one is the part of plastic inside undifferentiated waste which is burned to produce electrical energy and heat.

\footnotetext{
${ }^{5}$ Data are available at http://www.conai.org/en/about-us/conai-system/consortiums/

${ }^{6}$ Data are available at http://www.consorzioricrea.org/il-consorzio/i-numeri-del-2017/

${ }^{7}$ Data are available at http://www.conai.org/en/about-us/conai-system/consortiums/

${ }^{8}$ Data are available at http://www.conai.org/en/about-us/conai-system/consortiums/

${ }^{9}$ Data are available at http://www.comieco.org/i-nostri-risultati/i-risultati-di-riciclo.aspx

${ }^{10}$ Data are available at http://www.rilegno.org/il-mondo-rilegno/

${ }^{11}$ Data are available at http://www.rilegno.org/i-numeri/
} 
Thanks to its activity, more than $90 \%$ of Italian municipalities recycle plastic which allows to recover $867.000^{12}$ tons of material each year.

To conclude, Coreve recycles and recovers glass packaging waste. It was born in 1997 and every producer and importer of glass has to adhere: at the end of 2018 they were 27 producers and 94 importers $^{13}$.

The Environmental Protection National Network: ISPRA and AssoARPA

In 2017, the Environmental Protection National Network was born with the Law 132/2016 on the creation of the National Institution for the environmental protection and research [13]. This new system is more than the sum of ISPRA and ARPA's regional agencies: it's a consolidated network that synchronizes local environmental issues with national policies.

The Italian Institute for Environmental Protection and Research (ISPRA) ISPRA works with many European and international environmental scientific and technical institutes and organizations to carry out its institutional mandate and to strengthen the role of the national environmental protection agencies system within the international cooperation.

One computed measure offered by ISPRA is the Internal Material Consumption (IMC) index which measures how many resources have been transformed into new goods in a considered period. As Figure 3 illustrates, in 2016 the Italian IMC amounted to 515 million of tonnes with a total decrease of $41 \%$ since 1991 . This decrease was caused from 1991 to 2006 by a cyclical trend, and from 2006 by a constant decline which stopped in 2016, when it started to increase again. Consequently, in 2016 there was a total production waste increase, but it didn't last long and in 2017 it was 1,8\% lower than the previous year showing a contraction of production.

Besides, for a general look of the waste management activity, ISPRA calculates the Waste Recycled index. It measures the ratio between the recycled waste in one year and total waste produced in the same year. In 2017, the ratio measured $49,4 \%$ considering the percentage of urban waste recycling (as sum of organic, paper, glass, aluminium, plastic, and wood), and $43,9 \%$ considering the total urban waste recycled.

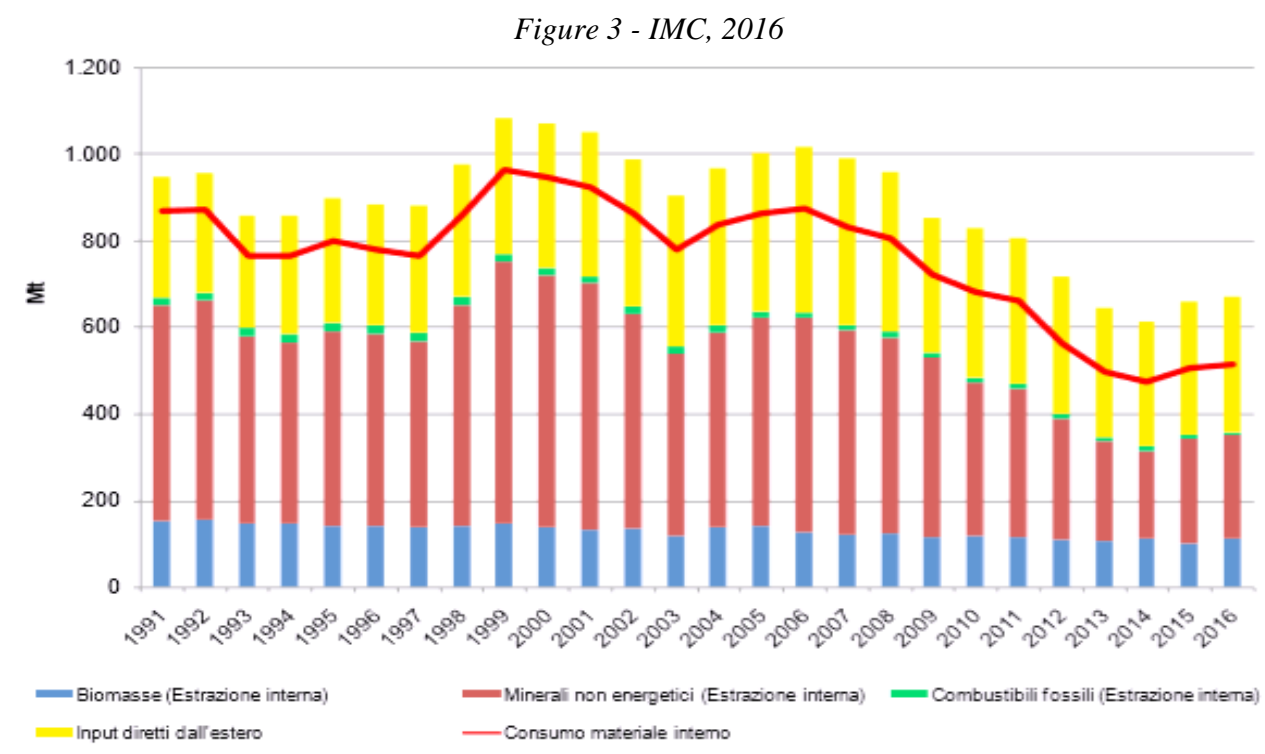

Figure 4, shows the portion of each component of the urban waste recycled for 2017. The organic component has the largest percentage (41.3\%) and this is a useful data to understand biomass relevance explained in Section 5. As explained before, once the organic waste is transformed it has a wide variety of implementation fields. According to its quality it can be used as fertilizer, to produce energy, or along highways.

\footnotetext{
${ }^{12}$ Data are available at http://www.conai.org/en/about-us/conai-system/consortiums/

${ }^{13}$ Data are available at https://coreve.it/chi-siamo/
} 


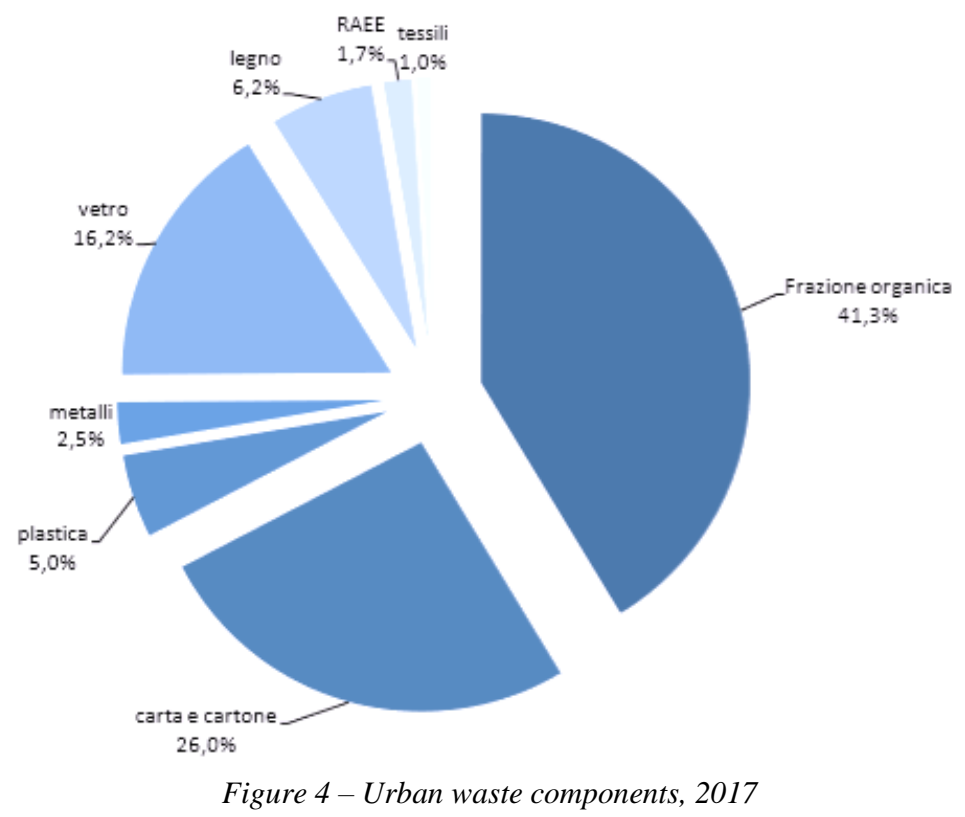

Furthermore, to analyze how waste is handled, Figure 5 demonstrates that landfilling accounts for the $23 \%$ of total waste management practices while recycling amounts to $47 \%, 18 \%$ is incinerated and only $1 \%$ of the total waste is sent to productive plants to produce energy in other production cycles. There is a small trend toward the adoption of greener waste management activities. Anyway, the hardest element to transform is people behaviour: they don't understand the benefits because they don't perceive them and they don't have a long term perspective. So, they prefer the easier way, even if it's the less ecological one. This is seen into stores where biological products are more expensive than others and people choose the less expensive alternative. In this way, customers are not rewarding those enterprises that adopt more sustainable solutions. This makes greener solutions less convenient than landfilling.

Figure 5 - Waste management, 2017

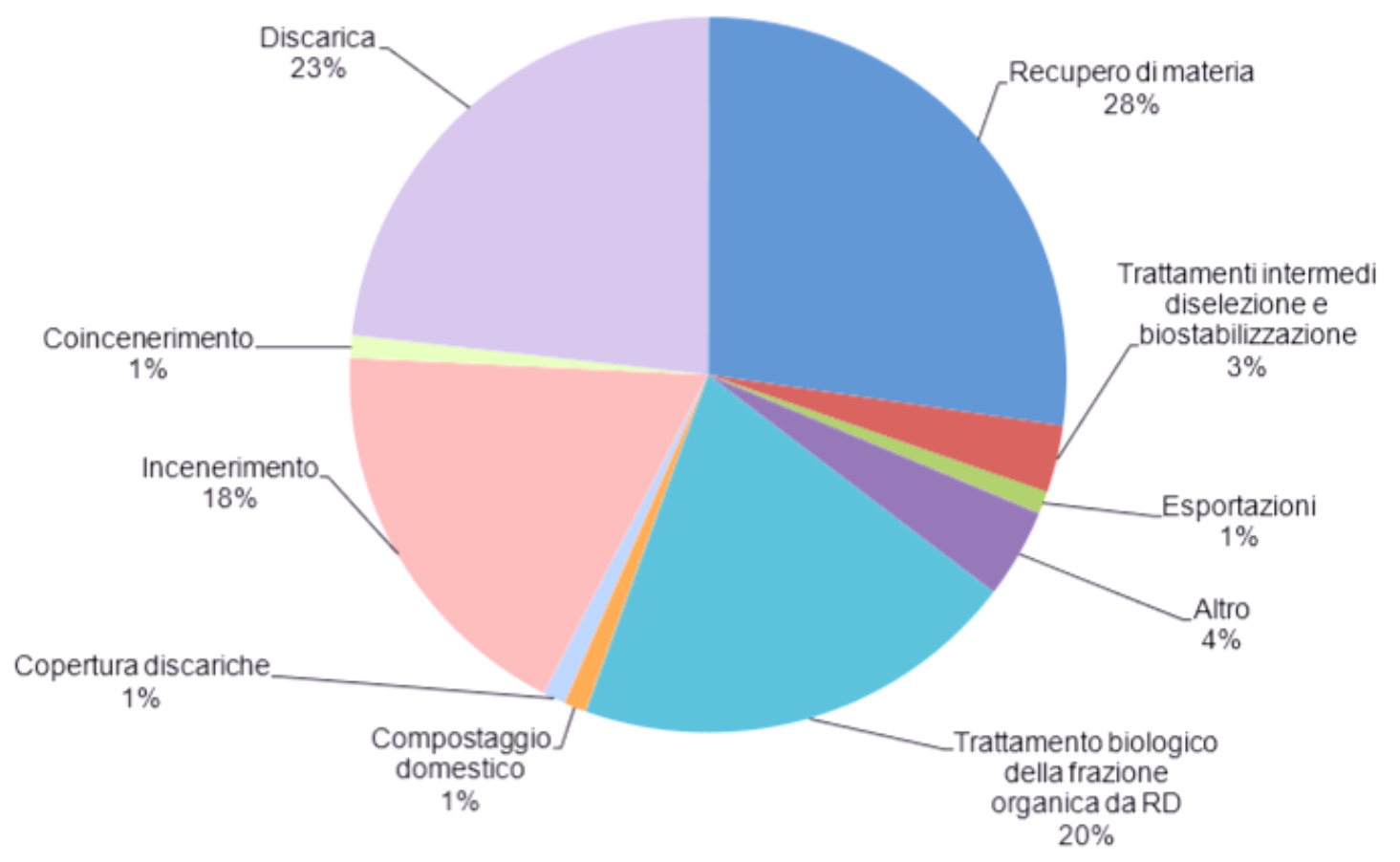

Then, AssoARPA is a non-profit Association of Environmental Protection Regional Agencies which was born at the end of 1990s.

Its characteristic of being a no-profit-oriented organization, together with the legal personality obtained in 
2015, helps to promote the activity of its associates. Furthermore, the legal personality allows the Agencies to have their own heritage.

It's an example of a consolidated federative system, made by 20 Regional and 2 Autonomous Provinces Agencies, that combines the direct knowledge of the territory with monitoring and controlling activities, which are aided by national and local policies related to environmental protection.

In 2016 special waste production accounted for 16.800 .724 tonnes, registering a decrease of $1.3 \%$ from 2015 , and considering Pavia, Bergamo, and Milano, Brescia was the area with the highest production due to the presence of production sites.

Special waste management decreased in 2016 because the total production decreased: the amount sent to disposal reduced of $35.2 \%$ while the reused component measures a constant $1 \%$ increase every year.

With regards to urban waste (UW) production, whose amount is proportional to population, in 2017 it amounted to 4.684 .043 tonnes, which is a $1.6 \%$ decrease compared to the previous year.

The quantity of UW collected through separate collection was 3.262.786 ( $+0.4 \%$ from 2016) accounting for $69,7 \%$ (against the $68.3 \%$ registered in 2016) of the total managed quantity; the quantity sent to reuse was equal to 2.771 .977 tonnes, the $60.9 \%$ on the total, providing a $90.2 \%$ of regenerated energy and material, an amount greater than 2016 when the total regenerated was $89.5 \%$.

\section{OPEN CHALLENGES AND POSSIBLE SOLUTIONS}

\section{The opportunities related to Biomass.}

The circular economy goals can be achieved if the "end-of-life" concept is replaced by a superior design of materials, products, systems and business models.

Renewable energy sources (RES) are a fundamental instrument to shape the clean global economy. Among RES, biomass has received greater scientific attention in the last years because it has environmental, economic and social advantages.

First, it provides a huge opportunity of energy generation, since the organic materials used into the process are always and widely available as well assignificant job creation. Secondarily, it is a carbon neutral activity, because biomass fuels release the same amount of carbon as the quantity absorbed during their life cycle, it's a natural step in photosynthesis. Third, biomasses are less expensive than fossil fuels, which require oil drills, gas pipelines and other infrastructures with a huge risk placed on the natural environment around drilling sites. Furthermore, biomass decreases the reliance on fossil fuels. Last, by being burned, the amount of final garbage that is dumped in landfills is reduced by 60 to $90 \%{ }^{14}$, reducing costs of disposal as well.

However, it has some shortcomings as well. Firstly, the energy obtained from biomass is not as efficient as fossil fuels and they are required to increase biofuels' efficiency. Furthermore, it may lead do deforestation because of the large amounts of woods that have to be burned to produce the desired amount of power. Lastly, it requires a lot of space and, by being placed in urban areas, they deteriorate the landscape.

A solution is carried out by the SynTech Bioenergy LLC, whose mission is the transformation of biomass, agricultural waste and MSW into renewable heat and electricity. They have created the BioMax ${ }^{15}$ technology which gasifies the agricultural waste to more than $800^{\circ} \mathrm{C}$ to generate syngas, a mixture of flammable gasses used to power engines inside the machine and make electricity. Not all the feedstock can be converted into syngas, what is left behind is the so-called biochar, a high quality, soil-enriching product used to improve food security, preserve agricultural diversity and much more.

The machine produces extremely low levels of tar (no other pollutants), requires low maintenance and reduced disposal costs, it's fully automated, operable $24 / 7$ and covers an area of $10 \mathrm{~m}^{2}$.

The benefits and the challenges of green finance.

Green finance (GF), defined as "the financing of investments that provide environmental benefits in the broader context of environmentally sustainable development" (see Falcone and Sica, 2019 [5]) can provide a significant contribution by assuring capital flow in RES sectors, while enhancing the sustainability of the overall financial system. It can foster firms' environmentally sustainable investments, that aim at the reduction of emissions, while the Country faces the transition to a decarbonized economy. Furthermore, GF is not limited to climate finance only, but includes all financial products and services that are aimed at other environmental objectives: think about industrial pollution control and water, biodiversity protection; it also takes into consideration the operational costs of green investments, such as project preparation and land acquisition costs.

\footnotetext{
${ }^{14}$ Data available at: https://www.syntechbioenergy.com/blog/biomass-advantages-disadvantages

${ }^{15}$ Further information can be found at: https://www.syntechbioenergy.com/biomax/
} 
Therefore, all GF instruments guide decisions by implementing risk assessment analysis that meet environmental sustainability standards.

So, investors are willing to invest in GF, considering ethical reasons and advantageous returns. In 2018 according to Landberg et al. (2019, [8]), Europe, United States, Japan, Canada and Australia held at least \$30,7 trillion of funds in green finance, with an increase of $34 \%$ from 2016. Europe held $€ 14$ trillion, accounting for the $48,4 \%$ of the total. This demonstrates that economic agents believe that "greener" investments are going to be a major growing business in the future. Anyway, they still account for one-third of the tracked assets under management. GF is still limited today also because of agents' short-term orientation: the funding of environmentally friendly projects require large upfront investments that generate cash flows and returns only in the long term.

Italy's banking, capital markets, insurance, investments and public finance sectors have taken some steps forward. As reported in Financing the Future 2016 ([19]) between 2007 and 2014 italian banks have lent $€ 27$ billion $^{16}$ for renewable energy; in 2016 the ranking of sustainability disclosure on 45 stock exchanges fixed Borsa Italiana at the 19th place, with over $22 \%$ of Italy's insurance markets covered by companies that have signed the UN Principles for Sustainable insurance.: In 2016 27,5\% of Italian companies can be defined coregreen (which means they produce goods or services with high environmental value), $14.5 \%$ are go-green (i.e. they have an environmental strategy and/or management system with high quality environmental standard in processes or design).

Despite the promising developments, these factors have led to insufficient flows of capital to the green economy. small and medium enterprises (SMEs) have limited access to capital, mainly due to adverse selection. Besides, intermediaries don't communicate relevant information to adequately appreciate the market performance of new green projects. This causes GF to be perceived as riskier than traditional financing, reducing the potential investment opportunities.

Moreover, at the moment there isn't a widely accepted definition of sustainability and some funds sell themselves as green or ethical, even though they aren't good for the environment.

One more issue that causes a constraint to GF is the uncertainty about government policies that should be certain, long-term oriented and supported by a clearly established regulatory framework.

Government policies should correct market failures that arise from subsidizing traditional fuel produces, which makes investments in the biomass sector uncompetitive. An example comes from the U.S. which, under the current presidential line, has resigned important environment and climate change international agreements on climate change regulations. The U.S. now promotes rules benefitting polluters.

Another relevant issue is concerned with the measurement of recycling performances. To this purpose Istat (the Italian National Statistic Institute) has elaborated a new set of indicators to be considered next to the traditional economic national indicator of GDP, and to address the State Budget Planning. These indicators are called BES (i.e. indicators of Equitable and Sustainable Well-being) and they are developed to go beyond GDP as the only measure of well-being. They represent twelve areas (health, eduction, work and work-life balance, wealth, social relations, politics and institutions, security, individual well-being, cultural heritage, environment, innovation and quality of services) and can be considered the precursors of SDGs. Today, a further development to make it coherent with the Agenda 2030 and SDGs is expected.

\section{CONCLUSIONS}

Many studies have carried out the benefits of circular economy, allowing the translation of theoretical benefits into effective regulation and clear business opportunities and making the circular economy more attractive than the idea of sustainable development.

Despite the results Italy has achieved, a lot of work is still required. We need to change our ideas and our perception of green economy, institutions must create long-term oriented laws, and enterprises need to implement these concepts in their missions and corporate values.

Italy could become a leading-role State in circular economy. To achieve that position, more investments are required and people, as well as enterprises and institutions, must change their mindset. These alternatives don't require only high investments, but years of training and a lot of communication and mass education. Full development of circular economy requires the general involvement of households both when the act as consumers and when they get free of their waste. As consumers, people must develop environment aware

\footnotetext{
${ }^{16}$ UN Environment, Ministero dell'Ambiente e Inquiry, Financing the future: Report of the Italian National dialogue on Sustainable Finance, 2016
} 
decision criteria. This includes the propensity to pay more for products that include good recycling design and materials, since such products tend to cost more.

Public authority is therefore mainly involved in the full development of circular economy. New regulations and public incentives can be effective solution to sustain to orientation of consumers towards the preference for products "circular economy" friendly. These objectives are becoming progressively urgent as time passes, since recycling and circular economy principles are fundamental elements of the UN Sustainable Development Goals and powerful activities to reduce the incumbent Climate Changes.

\section{BIBLIOGRAPHY}

[1] ANCI, CONAI, 2014, Framework Planning Agreement.

Available at: http://www.conai.org/enti-locali/accordo-quadro-anci-conai/

[2] Directive 2008/98/EC of the European Parliament and of the Council of 19 November 2008 on waste and repealing certain Directives (Text with EEA relevance).

[3] Decree Ronchi 22/1997 of 05/02/1997 "Implementation of Directives 91/156/CE on waste, 91/689/CEE on hazardous waste and 94/62/CE on packaging and waste from packaging".

[4] European Environment Agency, 2013, Report n.2/2013: Managing municipal solid waste - a review of achievements in 32 European countries.

Available at: https://www.eea.europa.eu/publications/managing-municipal-solid-waste\#tab-figuresused

[5] Falcone Marcello Pasquale, Edgardo Sica, Assessing the Opportunities and Challenges of Green Finance in Italy: an analysis of the biomass production sector, 2019.

Available at: https://www.mdpi.com/2071-1050/11/2/517

[6] Geyer, R., Jambeck, J. R., \& Law, K. L., 2017, Production, use, and fate of all plastics ever made, Science Advances.

Available at: https://advances.sciencemag.org/content/3/7/e1700782

[7] Haque Tajirul, 2019, Introduction to Electronics (e-waste) Recycling. Available at: https://www.thebalancesmb.com/introduction-to-electronics-e-waste-recycling-4049386

[8] Landberg Reed, Massa Annie and Pogkas Demetrios, 2019, Green Finance is now \$31 trillion and growing, Bloomberg.

Available at: https://www.bloomberg.com/graphics/2019-green-finance/

[9] Law 157/1992 and following amendments: Norme per la protezione della fauna selvatica omeoterma e per il prelievo venatorio.

[10] Law 61/1994 on Riorganizzazione dei controlli ambientali e istituzione dell'Agenzia nazionale per la protezione dell'ambiente.

[11] Law 16/1999 on Istituzione dell'Agenzia Regionale per la Protezione dell'Ambiente - ARPA.

[12] Law 133/2008 without amendments on "disposizioni urgenti per lo sviluppo economico, la semplificazione, la competitività, la stabilizzazione della finanza pubblica e la perequazione tributaria”.

[13] Law 132/2016 on the creation of the National Institution for the environmental protection and research.

[14] LeBlanc Rick, 2018, An introduction to metal recycling: an overview of metal recycling, its importance, and recycling processes.

Available at: https://www.thebalancesmb.com/an-introduction-to-metal-recycling-4057469

[15] LeBlanc Rick, 2019, Quick facts about glass recycling: glass recycling facts you should know. Available at: https://www.thebalancesmb.com/facts-about-glass-recycling-2877982

[16] Legislative Decree 152/2006 on the Environmental Code.

[17] Ritchie Hannah, Roser Max, 2018, Plastic Pollution.

Available at: https://ourworldindata.org/plastic-pollution

[18] The Circular Economy Network, ENEA, 2019, Report on The Circular Economy in Italy. Available at: www.circulareconomynetwork.it

[19] UN Environment, Ministero dell'Ambiente e Inquiry, Financing the future: Report of the Italian National dialogue on Sustainable Finance, 2016 